\title{
ALTERAÇÕES NA CLASSIFICAÇÃO DO MILHO DEVIDO À NOVA INSTRUÇÃO NORMATIVA Nº 60, DE 22 DE DEZEMBRO DE 2011
}

\author{
FERNANDO MENDES BOTELHO ${ }^{1}$, SÍLVIA DE CARVALHO CAMPOS BOTELHO², \\ ANTÔNIO SOARES NETO ${ }^{1}$ e SOLENIR RUFFATO ${ }^{1}$
}

${ }^{1}$ UFMT, Sinop, MT, Brasil,fernando.botelho@ufmt.br, antoniosoaresn@gmail.com,sruffato@ufmt.br

${ }^{2}$ Embrapa Agrossilvipastoril, Sinop, MT,Brasil, silvia.campos@embrapa.br

Revista Brasileira de Milho e Sorgo, v.12, n.1, p. 61-67, 2013

\begin{abstract}
RESUMO - Objetivou-se analisar, de forma comparativa, a qualidade de grãos de milho da safra 2008/2009 produzidos e armazenados em municípios de Mato Grosso (Nova Mutum, Lucas do Rio Verde, Sorriso e Sinop) pela portaria vigente e pela instrução normativa que entrará em vigor em 2013. O produto foi classificado por um profissional credenciado junto ao Ministério da Agricultura, Pecuária e Abastecimento, segundo a portaria vigente (Portaria ${ }^{\circ}$ 845, de 8 de novembro de 1976) e pela nova Instrução Normativa ( $\left(\mathrm{N} \mathrm{n}^{\circ}\right.$ 60, de 22 de dezembro de 2011), que entrará em vigor em 01 de setembro de 2013. Diante dos laudos de classificação e utilizando as instruções contidas na Portaria $\mathrm{n}^{\circ} 845$ e na IN ${ }^{\circ} 60$, verificaram-se diferenças, principalmente, nos teores de impurezas e de grãos quebrados. A diferença entre estes dois índices modificou a classificação por tipo. Algumas amostras classificadas como "tipo 1" (Portaria n ${ }^{0} 845$ ) passaram a "tipo 3" (IN n 60 ) e classificadas como "abaixo do padrão" (Portaria n ${ }^{\circ} 845$ ) passaram para "tipo 1" (IN n $\left.{ }^{\circ} 60\right)$. Para as demais classes de defeitos, não foram observadas diferenças consideráveis entre as duas legislações.
\end{abstract}

Palavras-chave: Zea mays; qualidade; impurezas; avarias.

\section{CHANGES IN RATING DUE TO THE NEW CORN INSTRUCTION}

\begin{abstract}
The objective of this work was to analyze comparatively the quality of corn, 2008/2009 season, produced and stored in counties of Mato Grosso State (Nova Mutum, Lucas do Rio Verde, Sorriso and Sinop) statement by current regulations and new instruction normative that come into force in 2013 . The product has been classified by a professional accredited by the Brazilian Ministry of Agriculture and Food Supply, according to the normative instruction (IN) legislation (Ordinance $n^{\circ} 845$, November 8, 1976) and the new IN (Instruction $n^{\circ} 60$, December 22, 2011), which will enter into force on September 1st, 2013. Given the reports of classification using the instructions provided in Ordinance $n^{\circ} 845$ and Instruction $n^{\circ} 60$, there were differences mainly in the levels of impurities and broken grains. The difference between these two indexes has changed the classification by type, so that some samples classified as "type 1" (Ordinance $n^{\circ}$ 845) passed the "type 3" (IN 60) and classified as "substandard" (Ordinance $\mathrm{n}^{\circ} 845$ ) to "type 1 " (IN 60). For other classes of defects significant differences were not observed between the legislations.
\end{abstract}

Key words: Zea mays; quality; impurities; damages. 
A produção mundial de milho (Zea mays L.) em 2011 chegou à marca dos 835 milhões de toneladas, sendo o consumo previsto de 827,9 milhões de toneladas (USDA, 2011). O Brasil é o terceiro maior produtor do mundo, atrás apenas dos Estados Unidos e da China.

$\mathrm{Na}$ safra 2010/2011, no estado de Mato Grosso, foram produzidos 7,2 milhões de toneladas de grãos numa área de 1,8 milhão de hectares. Desse total, somente no município de Sorriso, localizado no eixo da BR 163, Centro-Norte de Mato Grosso, foi cultivada uma área de 220.000 ha, com uma produção correspondente de 1,1 milhão de toneladas deste grão (Conab, 2011).

Além da preocupação constante com a quantidade a ser produzida e comercializada, a qualidade de um produto para o consumo deve estar em padrões aceitáveis de higiene e nutrição. Para a comercialização de diversos grãos, a qualidade de um produto é mensurada pelo processo de classificação, que supõe a existência de um padrão. Em síntese, classificar é determinar a qualidade extrínseca e intrínseca de um produto a partir de padrões.

A classificação e a padronização, entretanto, são utilizadas não apenas como uma ferramenta de avaliação de qualidade de produtos oferecidos. Os laudos gerados a partir da classificação de um lote de grãos são hoje uma exigência dos consumidores finais, que buscam a cada dia produtos com qualidade garantida, que atendam padrões de segurança alimentar, regularidade e consistência dos produtos e serviços oferecidos. Dessa forma, a classificação assume um papel relevante sempre que for associada à comercialização, ao controle e à manutenção de qualidade de qualquer produto, inclusive os agrícolas.

O milho, atualmente, é classificado com base na Portaria $\mathrm{n}^{\mathrm{o}} 845$, de 08 de novembro de 1976 , que passou por uma atualização do padrão descrito em 12 de abril de 1996 (Portaria SDR/MA nº 11).

A classificação é um processo dinâmico e que deve passar por ajustes de acordo com os interesses das partes envolvidas. No caso do milho, alterações nas normas de classificação estão sendo propostas, considerando a necessidade premente da utilização e da uniformização dos procedimentos. Assim, uma nova norma para padronização da qualidade do milho entrará em vigor em setembro de 2013 (BRASIL, 2012). Essas alterações, entretanto, necessitam de uma discussão ampla a fim de se encontrar o equilíbrio nas exigências das diversas partes. Segundo levantamentos de cooperativas, como Coamo, Cocamar e Agrária, caso a proposta original apresentada pelo Ministério da Agricultura, Pecuária e Abastecimento (Mapa) entrasse em vigor no mês de julho de 2012 , de 30 a $75 \%$ da primeira e da segunda safra de milho poderiam desenquadrar de tipo (SISTEMA FAEP, 2011). Esta constatação levantou a necessidade de rediscutir alguns pontos das normas de classificação, de modo a adequar à realidade brasileira e, desta forma, a nova instrução normativa de classificação do milho (IN n ${ }^{\circ} 60$ ) passará a vigorar a partir de $1^{\circ}$ de setembro de 2013.

A principal mudança entre a portaria atual $\left(n^{\circ} 845\right)$ e a IN $n^{\circ} 60$ que entrará em vigor em 2013 são as peneiras de classificação, sendo que a legislação atual exige uso de peneira de crivos circulares com diâmetro de $5,00 \mathrm{~mm}$ e, pela nova instrução normativa, dever-se-á utilizar peneiras de crivos circulares de 5,00 mm e de 3,00 mm. Além disso, a IN $n^{\circ} 60$ prevê ainda a redução da tolerância da quantidade de grãos ardidos, de matérias estranhas, de impurezas e de fragmentos. Os defeitos "grãos quebrados" e "grãos carunchados" passarão a ser analisados isoladamente, determinando tipo. O percentual 
de umidade recomendado para a comercialização de grãos de milho será de $14,0 \%$ e não mais $14,5 \%$, como previsto na Portaria $n^{\circ} 845$. Ademais, com o uso da IN n ${ }^{\circ} 60$, haverá alteração nas classificações quanto ao grupo (com a exclusão do grupo mole e inclusão do grupo dentado), quanto à classe, uma vez que foi incluída a classe "cores", e quanto ao tipo, com exclusão do tipo "Abaixo do padrão" e inclusão da tipologia "Fora de tipo".

Diante do exposto, o objetivo deste trabalho foi avaliar e comparar os resultados da classificação de grãos de milho de quatro municípios localizados na região Centro-Norte do estado de Mato Grosso baseados na portaria vigente e na nova instrução normativa de classificação do milho.

A classificação das amostras avaliadas neste trabalho foi realizada em uma empresa privada, localizada em Sorriso, MT e credenciada pelo Ministério da Agricultura Pecuária e Abastecimento (Mapa) e pela Companhia Nacional de Abastecimento (Conab) para prestar serviços de classificação de grãos.

Foram utilizados grãos de milho do estoque regulador, provenientes da safra 2008/2009 oriunda dos municípios de Nova Mutum, Lucas do Rio Verde, Sorriso e Sinop, armazenados tanto a granel quanto em sacaria. Em cada município, foram amostradas duas unidades armazenadoras (UAs), seguindo regulamentação descrita no artigo $7^{\circ}$ da Portaria SDR/MA n 11/96 (BRASIL, 1976).

As amostras compostas foram embaladas em sacos de polipropileno e imediatamente enviadas para a empresa de classificação, onde foram mantidas em laboratório climatizado por 3 a 5 dias até serem classificadas.

O processo de classificação consistiu, inicialmente, na homogeneização e na redução das amostras compostas para uma amostra média e, posteriormente, para uma amostra de trabalho. Este procedimento foi realizado utilizando-se um homogeneizador tipo Boerner e um quarteador inox de 16 canaletas. No caso do milho, a amostra média e a amostra de trabalho apresentam, respectivamente, $1000 \mathrm{~g}$ e $250 \mathrm{~g}$.

Cada amostra foi peneirada em movimentos repetitivos por $30 \mathrm{~s}$, utilizando-se peneiras de crivos circulares, indicadas para o milho, sobre uma peneira com um crivo menor que o anterior, acoplada a um fundo metálico, a fim de retirar as impurezas e as matérias estranhas, de modo que tudo que vazasse pela peneira seria considerado matéria estanha. Detritos que, porventura, ficaram retidos na peneira foram retirados manualmente. As amostras foram submetidas ao processo de classificação utilizando-se uma peneira de 5,0 mm (conforme Portaria $\mathrm{n}^{\circ}$ 845 , de 8 de novembro de 1976) e as peneiras de 5,0 e 3,0 mm (simulando a Instrução Normativa $n^{\circ} 60$, de 22 de dezembro de 2011).

Depois de retiradas as impurezas, determinou-se o teor de água da amostra, utilizando-se um determinador de umidade indireto modelo G 919, Gehaka, em três repetições. Todas as amostras classificadas apresentaram teores de água entre 11,5 e $12,0 \%$, isto é, dentro do exigido para comercialização, que é até $14 \%$.

Para efeito de comparação, foi utilizado um modelo único de laudo para ambas as normativas, de modo que foram quantificados individualmente os seguintes grupos de avariados: mofados; ardidos; brotados; total de mofados, ardidos e brotados; fermentados até um quarto; carunchados; chochos e imaturos; prejudicados por diversas causas; quebrados e total de avariados. Cada grupo de defeitos encontrado foi determinado utilizando-se balança com 
resolução de $0,01 \mathrm{~g}$. Após a quantificação dos defeitos, realizou-se o enquadramento dos lotes amostrados em tipos, de acordo com artigo $4^{\circ}$ da Portaria $n^{\circ}$ $845 / 76$ e com o artigo $5^{\circ}$ da $\mathrm{IN} \mathrm{n}^{\circ} 60 / 11$.

Os resultados das classificações pela portaria vigente e a nova instrução normativa quanto aos principais defeitos (ardidos, fermentados, fermentados até um quarto, impurezas, mofado, carunchado e quebrado) e quanto ao resultado por tipo foram comparados de forma descritiva.

Os dados referentes ao percentual de impurezas e aos grãos quebrados observados nos laudos de classificação dos grãos de milho das diferentes unidades armazenadoras amostradas estão apresentados na Figura 1.

Na Figura 1A, podem-se observar diferenças quanto ao percentual de impurezas nos grãos armazenados. Essas diferenças ocorreram quando se comparam as unidades armazenadoras dentro de um mesmo município e entre os municípios amostrados, independente da norma utilizada, fato que pode ser considerado normal, visto que esse produto é advindo de diferentes produtores e condições de produção.

Pela IN n ${ }^{\circ} 60$, em todas as UAs, houve redução nos percentuais de impureza em relação ao valor obtido considerando-se a portaria vigente, de modo que o valor máximo observado para esse índice foi de aproximadamente $0,5 \%$, ou seja, bem abaixo do permitido para comercialização (1\%). Isto se deve ao fato de que a $\mathrm{IN} \mathrm{n}^{\circ} 60$ não estabelece como impureza materiais particulados presentes na massa de grãos que tenham diâmetro mínimo igual a 3,0 mm.

Esse resultado pode afetar o armazenamento de forma prática, uma vez que o espaço intergranular da massa de grãos, caracterizado pela porosidade, é fundamental para a realização de qualquer tipo de operação unitária, principalmente aquelas que necessitam de algum tipo de movimentação de ar no produto, como nas operações de aeração, resfriamento e secagem, por exemplo. Desta forma, a possibilidade de armazenar produtos com maior quantidade de material particulado deve ser vista com cautela pelo armazenista, uma vez que o aumento dos particulados pode causar, no momento em que for necessária, alguma dessas operações. Vale ressaltar, ainda, que os sistemas de ventilação já instalados podem não funcionar adequadamente, por não terem sido dimensionados para atender situações com baixa porosidade da massa de grãos, como também salientam Corrêa et al. (2001).

Conforme observado na Figura 1B, a classificação dos grãos em relação ao percentual de quebrados variou entre os municípios e entre as unidades armazenadoras, assim como observado para os percentuais de impurezas.

Todavia, na comparação dos teores de impurezas, notou-se que a classificação pela Instrução Normativa $n^{\circ} 60$ reduziu consideravelmente o percentual de quebrados na massa de grãos de todas as unidades armazenadoras. Assim como foi verificado para o percentual de impurezas, esta IN não considera como grão quebrado grande parte do material presente na massa de grão que não seja grão inteiro.

O resultado final por tipo das amostras classificadas dos municípios de Sorriso, Lucas do Rio Verde, Sinop e Nova Mutum, de acordo com a Portaria vigente e com a IN no 60 , está apresentado na Tabela 1.

Nota-se que apenas no município de Nova Mutum os resultados foram iguais, para a classificação por tipo, para uma mesma amostra classificada pelas duas normativas (Tabela 1).

Nos outros três municípios, houve diferenciação por tipo, sendo que, considerando uma 

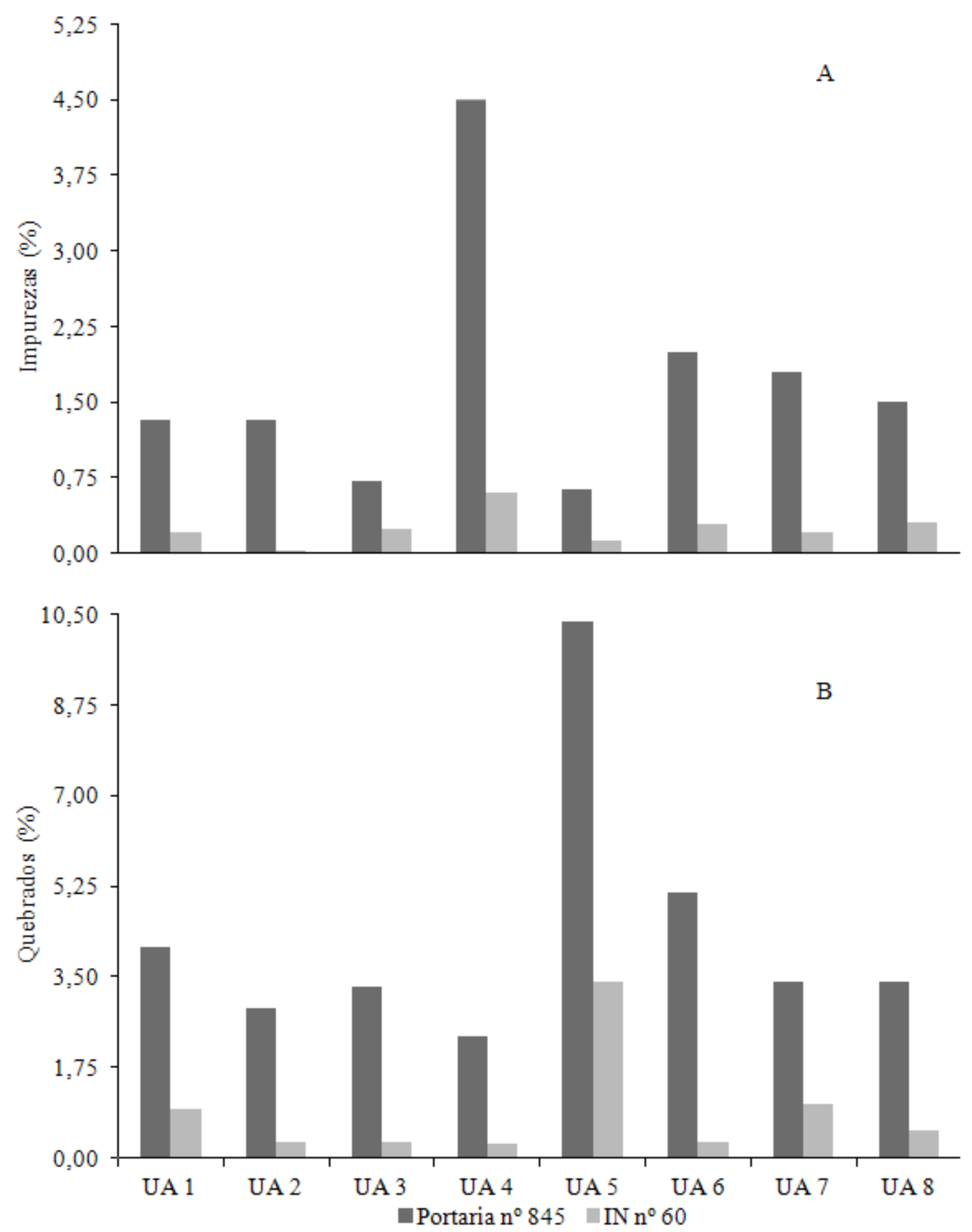

FIGURA 1. Porcentagem de impurezas e de grãos quebrados observados nas amostras de unidades armazenadoras (UA) dos municípios de Sorriso (UA1 e UA2), Lucas do Rio Verde (UA3 e UA4), Nova Mutum (UA5 e UA6) e Sinop (UA7 e UA8), classificadas pela Portaria $n^{\circ}$ 845, de 8 de novembro de 1976, e pela Instrução Normativa ${ }^{\circ}$ 60, de 22 de dezembro de 2011. 
mesma amostra classificada, o resultado passou do melhor (Tipo 1) para o pior (Tipo 3), como pode ser visto na UA1, do município de Sorriso; assim como ocorreu o inverso na UA5, em Lucas do Rio Verde, em que o milho classificado com base na portaria vigente foi classificado como abaixo do padrão e a mesma amostra, pela $\mathrm{IN} \mathrm{n}^{\mathrm{o}} 60$, enquadrou-se como sendo Tipo 1.

Essa inversão de resultados da classificação quanto aos tipos é possível de acontecer e, neste caso, ocorreu principalmente em função dos quesitos "grãos quebrados" e "grãos carunchados", que passaram a definir tipo individualmente na $\mathrm{IN} \mathrm{n}^{\circ} 60$. As unidades armazenadoras do município de Sorriso (UA1 e UA2) foram exemplos em que o percentual de carunchados definiu o tipo, sendo que foram encontrados $3,48 \%$ e $10,56 \%$ nas unidades 1 e 2 , respectivamente.

De acordo com a portaria vigente, todo material que passar na peneira de crivo de $5 \mathrm{~mm}$ é considerado como fragmento e é somado às impurezas e/ ou à matéria estranha. Já com a $\mathrm{IN} \mathrm{n}^{\circ} 60$, parte dos grãos quebrados será considerada sadia, sendo estes os grãos que passarem pela peneira de crivo $5,00 \mathrm{~mm}$, mas que ficarem retidos na peneira de crivo $3,0 \mathrm{~mm}$.

Outro aspecto importante é o defeito "grãos carunchados", pelo qual, a partir da nova instrução normativa, passam a não serem somados aos "avariados", como os grãos danificados, fermentados até um quarto do grão, quebrados, chochos e imaturos, para enquadrar a amostra classificada em tipo no total de avariados. Pela IN $n^{\circ} 60$, a presença de mais de $4,0 \%$ de grãos carunchados enquadra o produto como "fora de tipo".

À exceção do percentual de impurezas, de grãos quebrados e de grãos carunchados, não foi observada diferença no teor das demais avarias, uma vez que estas não sofreram alterações na forma de quantificá-las, considerando-se a normativa vigente em relação à $\mathrm{IN} \mathrm{n}^{\circ} 60$.

Sendo assim, a partir dos resultados deste trabalho, verificou-se que a classificação do milho variou de acordo com a instrução normativa utilizada principalmente devido à forma de quantificação e aos limites de tolerância para os grãos quebrados e as impurezas.

TABELA 1. Resultados da classificação por tipo entre a Portaria n ${ }^{\circ} 845$ e a IN nº 60 para as UAs dos municípios analisados.

\begin{tabular}{|c|c|c|c|}
\hline \multirow{2}{*}{ Município } & \multirow{2}{*}{$\begin{array}{c}\text { Unidade } \\
\text { armazenadora }\end{array}$} & \multicolumn{2}{|c|}{ Normativa } \\
\hline & & Portaria $\mathrm{n}^{\circ} 845$ & Instrução Normativa $n^{\circ} 60$ \\
\hline \multirow{2}{*}{ Sorriso, MT } & 1 & Tipo 1 & Tipo 3 \\
\hline & 2 & Tipo 3 & Fora de Tipo \\
\hline \multirow{2}{*}{ Nova Mutum, MT } & 3 & Abaixo do padrão & Fora de Tipo \\
\hline & 4 & Tipo 1 & Tipo 1 \\
\hline \multirow{2}{*}{ Lucas do Rio Verde, MT } & 5 & Abaixo do padrão & Tipo 1 \\
\hline & 6 & Tipo 1 & Tipo 1 \\
\hline \multirow{2}{*}{ Sinop, MT } & 7 & Tipo 2 & Tipo 1 \\
\hline & 8 & Tipo 1 & Tipo 1 \\
\hline
\end{tabular}




\section{Referências}

BRASIL. Instrução Normativa $n^{\circ}$ 60, de 22 de dezembro de 2011. Estabelece o Regulamento Técnico do Milho. Diário Oficial [da República Federativa do Brasil], Brasília, DF, n. 246, 23 dez. 2011. Seção 1, p. 3-5.

BRASIL. Portaria ${ }^{\circ}$ 611, de 04 de julho de 2012. Alterar os incisos IV e VI do art. 25 e o art. 31, todos da Instrução Normativa $n^{\circ} 60$, de 22 de dezembro de 2011. Diário Oficial [da República Federativa do Brasil], Brasília, DF, n. 129, 5 jul. 2012. Seção 1, p. 10.

BRASIL. Portaria $\mathrm{n}^{\circ} 11$, de 12 de abril de 1996. Uniformização dos critérios para classificação do milho (Zea mays L.) para o mercado interno. Diário Oficial [da República Federativa do Brasil], Brasília, DF, 15 abr. 1996. Seção 1, p. 6231.

CONAB. Acompanhamento da safra brasileira. Intenção de plantio. Primeiro levantamento. Outubro 2010. Disponível em: <http://www. conab.gov.br/OlalaCMS/uploads/arquivos/ fc9304890a88b451d5d992377687b0f9.pdf >. Acesso em: 8 nov. 2011.
CORRÊA, P. C.; GUIMARÃES, W. T.; AFONSO JÚNIOR, P. C. Efeito do nível e do tamanho de impurezas nas propriedades físicas da massa granular de feijão. Revista Brasileira de Engenharia Agrícola e Ambiental, Campina Grande, v. 5, p. 97-100, 2001.

USDA Department of Agriculture. Disponível em: $<\mathrm{http}: / /$ www.formatto.com.br/aguia/new.index.php/ component/content/artic35/lastnews/220-milhousda-projeta-safra-mundial-201112-de-83159milhões-detoneladas.11.05.11>. Acesso em: 8 nov. 2011.

SISTEMA FAEP. Fundação da Agricultura do Estado do Paraná. Mapa divulga nova classificação do milho. 2011. Disponível em: http://www.sistemafaep.org. br/noticia.aspx?id=1016. Acesso em: 10 out. 2012.

BRASIL. Ministério da Agricultura, Pecuária e Abastecimento. Portaria $\mathbf{N}^{\mathbf{0}} \mathbf{8 4 5}$ de 8 de novembro de 1976. 1976. 7 p. Disponível em: <http://www. claspar.pr.gov.br/ arquivos/File/pdf/milho845_76. pdf $>$. Acesso em: 24 maio 2012.

BRASIL. Ministério da Agricultura, Pecuária e Abastecimento. Instrução Normativa $\mathrm{N}^{\circ} 60$, de 22 de dezembro de 2011. Diário Oficial da União, DF, 23 dez. 2011. p. 3, Seção 1. 